\title{
Heads of Households' Educational Attainment and Households Food Insecurity and Monetary Poverty in Burkina Faso: A Joint Semi-parametric Bivariate Modeling Approach
}

\author{
Ibrahim Niankara \\ College of Business, Al Ain University of Science and Technology, P.O. Box: 112612, Abu Dhabi, UAE; Tel: \\ +97124444696 Ext: 539 ; Fax: +97124444304; E-mail: ibrahim.niankara@aau.ac.ae
}

\begin{abstract}
Given the Income enabling nature of education as stipulated by human capital theory, it can be postulated that "ceteris paribus", households with formally educated heads experience less food insecurity and monetary poverty than those with uneducated heads. We test this claim in the case of Burkina Faso, using the 2014 National Survey on Households Living Conditions, along with semi-parametric modeling techniques.

In its design the study uses households "willingness and ability" to spend annually on food consumption a per-capita amount above the food poverty line of 102,040 CFA Franc to characterize " household food security", and households "unwillingness or inability" to spend above the overall poverty line of 153,530 CFA Franc to characterize "monetary poverty". In addition, the study relies not only on single equation multivariate probit and logit specifications, but also on both fully parametric and semi-parametric bivariate probit representations of food insecurity and monetary poverty.

The results show that relaxing the linearity and independence assumptions through joint semiparametric bivariate modeling captures better the true effects of heads of households' educational attainment on households' food insecurity and monetary poverty. In fact, compared to households headed by someone with no education, those headed by someone with a primary, secondary or higher education are respectively $19.8 \%, 49.7 \%$ and $118.9 \%$ less likely to experience food insecurity, and respectively 40.1\%, $77.0 \%$ and $172.3 \%$ less likely to experience monetary poverty in Burkina Faso. In addition, the experience of food insecurity and monetary poverty are highly correlated at $92.7 \%$, suggesting that educational policies that alleviate poverty in Burkina Faso should also impact positively food security in the country.
\end{abstract}

Keywords: Burkina Faso, Discrete Choice, Education, Food Insecurity, Monetary Poverty JEL: C50, I20, I32, O50 


\section{Introduction}

Nearly one-half of Sub-Saharan Africa's population is living in extreme poverty and depending heavily on agriculture and natural resources either directly or indirectly for their incomes and food security (Bremner, 2012). Chronic undernourishment is widespread throughout the region, with the greatest incidence occurring in conflict countries, often endowed with abundant mineral resources. The region as a whole remains susceptible to frequent food crises and famines which are easily triggered by even the lightest of droughts, floods, pests or economic downturns Coates et al. (2006).

The region's food supply is mainly made of cereals, roots and tubers, however their production has generally lagged behind the rate of population growth (Ehui, 2002). As a result, countries in the region have had to rely increasingly on imports to satisfy the demand for food, especially those with already negative trade balances and high debt, for which these imports are not sustainable(Kidane et al., 2006; Altman et al., 2009). Access to food by households in the region is therefore undermined by the inability of the countries to generate the resources required for food import(Kruger et al. 2006). Also contributing to this fact is a high and increasing level of poverty resulting from over-dependence on subsistence agriculture, limited access to off-farm employment, sluggish development in urban areas and skewed income distribution (SESRTCIC, 2007).

The world food summit of 1996 defined "National food security" as a state in which "all people, at all times, have physical and economic access to sufficient, safe, and nutritious food to meet their dietary needs and food preference for an active and healthy life" (Melgar-Quinonez et al. 2006). Disaggregating at the household level, we could then extrapolate the definition of "Household food security" which is the one embraced throughout this analysis, as a state in which "all household members, in a given time period (for example a year) have physical and economic access to sufficient, safe, and nutritious food to meet their dietary needs and food preference for an active and healthy life". Although the former definition is broad and universal in nature, the later definition is focused and contemporaneous allowing us to characterize household level heterogeneity in food security, as opposed to the initial definition which characterizes country level variations in food security.

Hunger has long been a concern of world leaders, as evidenced by the 1948 Universal Declaration of Human Rights (Melgar-Quinonez et al., 2006), stating that "Everyone has the right to a standard of living adequate for the health and well-being of himself and of his family, including food...". As part of the millennium development goals (MDGs), UN country members in 1996 reaffirmed access to adequate, safe, and nutritious food as a fundamental right for inhabitants throughout the world. This commitment was further reiterated in 2015 through the 2030 sustainable development goals (SGDs).

With support from its development partners, and under the MDGs Burkina Faso has achieved notable progress in many sectors such as education (IFAD, 2012). Nevertheless, serious delays are 
still apparent in other areas including reducing poverty and hunger GARRIDO and SÁNCHEZ, 2015). According to a USAID report (USAID, 2015a), Burkina Faso's agricultural sector continues to generate roughly a third of the country's GDP and employ $80 \%$ of the population. However, the agricultural sector is still characterized by low crop and livestock productivity and mainly supports subsistence livelihoods (Zidouemba and Gérard, 2014; FARA, INERA, ZEF, 2015). Moreover, 3.5 million people or roughly $20 \%$ of the population, are still experiencing food insecurity and approximately $50 \%$ of rural households unable to produce sufficient quantities of food to sustain daily caloric intakes (USAID, 2014).

Because of the close association however between food insecurity and poverty (USAID, 2015b), strategies that alleviate poverty should have positive impacts on food security. The analysis of the state of poverty and education in Burkina Faso shows a low rate of education and a high rate of poverty among households living in the country (INSD, 2015). Because the educational choices made by households members also influence their consumption choices which in turn defines households' food security and poverty, research offering insights on how education impacts households' spending choices in Burkina Faso is of relevance.

It's therefore with this aim in mind that an initial study was implemented using the 2009 national survey on households' living conditions in Burkina Faso. The present study updates and extends this former study, by offering opportunities to make further policy recommendations to reduce households' food insecurity and monetary poverty, as a way of improving standards of living in Burkina Faso. The specific extensions introduced by the current analysis are as follows:

1. It uses the most up to date version of the same survey, namely the 2014 national survey on households living conditions in Burkina Faso,

2. It breaks down poverty into "food-poverty" and "monetary poverty" allowing us to also characterize the issue of food insecurity in Burkina Faso,

3. Methodologically speaking, this study also innovates on the former by:

- comparing the performance of the multivariate logit and probit models, so as to choose the best framework for describing the food insecurity and monetary poverty processes,

- furthermore relaxing the implicit independence assumption between "food poverty" and "monetary poverty" in the single equation multivariate logit and probit models, using a bivariate probit framework that models them jointly,

- finally relaxing the linearity assumption in the standard bivariate probit model, using a semi-parametric approach that models the head of household "age" and "household size" variables with general copula functions, so as to capture their true and potentially non-linear effects on food insecurity and monetary.

In introducing these extensions, the broad objective of the current study is to understand the nature of the effects that heads of households educational attainment has on households' food 
security and overall poverty in Burkina Faso. More specifically, the analysis addresses the following three important questions:

Question1: Do households with formally educated heads experience food insecurity to the same extent as do those headed by uneducated heads in Burkina Faso ?

Question2: Do households with formally educated heads experience monetary poverty to the same extent as do those headed by uneducated heads in Burkina Faso ?

Question3: Are the incidences of households' food insecurity and monetary poverty independent in Burkina Faso?

In relation to the above three questions, we formulate the following hypothesis:

H1: All things being equal, there is no significant difference between households with formally educated heads and those with uneducated heads in their experience of food insecurity in Burkina Faso;

H2: All things being equal, there is no significant difference between households with formally educated heads and those with uneducated heads in their experience of monetary poverty in Burkina Faso;

H3: All things being equal, the incidences of households' food insecurity and monetary poverty are independent in Burkina Faso.

In our quest to test the above three hypotheses, we organize the remaining of this paper as follows: Section 2 describes our extended economic model of spending choices and poverty status; Section 3 presents the data and analytical strategy for model identification; Section 4 presents the results of the analysis, while section 5 provides discussions and concludes the analysis

\section{The Extended Economic Model of Spending Choices and Poverty Status}

In this extended random utility formulation it is assumed that a household chooses between two spending alternatives for each consumption type $i$ (with $i=1$ if food consumption, and $i=2$ if overall consumption), spending either an amount of income below the poverty lines (such that: FoodPovStat $=0$, MoneyPovStat $=0$ ), or an amount of income above the poverty lines (such that: FoodPovStat $=1$, MoneyPovStat $=1$ ). These two alternatives are indexed respectively with 0 and 1 for each consumption type $i$, according to which one provides the highest satisfaction or utility. The discrete outcome variables (FoodPovStat, MoneyPovStat) then take the value 1 if alternative 1 has the highest utility, and the value 0 if alternative 0 has the highest utility. Additive random utility modeling (ARUM) specifies the utilities of alternatives 0 and 1 for each consumption type $i$ for $i=1,2$ to be:

$$
\begin{aligned}
& U_{i 0}=V_{i 0}+\epsilon_{i 0}, \\
& U_{i 1}=V_{i 1}+\epsilon_{i 1},
\end{aligned}
$$


where $V_{i 0}$ and $V_{i 1}$ are deterministic components of utility with $\epsilon_{i 0}$ and $\epsilon_{i 1}$ being the random components of utility. We observe $y_{i}=1$, if $U_{i 1}>U_{i 0}$, that is if alternative 1 has the highest utility of the two. Because of the presence of the random components of utility this is a random event with

$$
\begin{aligned}
\operatorname{Pr}\left[y_{i}=1\right] & =\operatorname{Pr}\left[U_{i 1}>U_{i 0}\right] \\
& =\operatorname{Pr}\left[V_{i 1}+\epsilon_{i 1}>V_{i 0}+\epsilon_{i 0}\right] \\
& =\operatorname{Pr}\left[\epsilon_{i 0}-\epsilon_{i 1}<-\left(V_{i 0}-V_{i 1}\right)\right] \\
& =F\left(V_{i 0}-V_{i 1}\right),
\end{aligned}
$$

where $F($.$) is the cumulative distribution function of the error differences \left(\epsilon_{i 0}-\epsilon_{i 1}\right)$. giving

$$
\operatorname{Pr}\left[y_{i}=1\right]=F\left(X^{\prime} \beta_{i}\right) \text { if } V_{i 0}-V_{i 1}=X^{\prime} \beta_{i}
$$

The ARUM requires a scale normalization since, if $U_{i 1}>U_{i 0}$ then $a U_{i 1}>a U_{i 0}$. This is usually done by specifying the variance of $\left(\epsilon_{i 0}-\epsilon_{i 1}\right)$. Different specifications for the distributions of the error terms $\left(\epsilon_{i 0}\right)$ and $\left(\epsilon_{i 1}\right)$ give different $F($.$) and hence different discrete choice models. The$ logit model is obtained when $F\left(X^{\prime} \beta_{i}\right)=\Lambda\left(X^{\prime} \beta_{i}\right)$, that is the type 1 extreme value cumulative distribution function, with choice probability given by:

$$
\operatorname{Pr}\left[-\left(\epsilon_{i 0}-\epsilon_{i 1}\right)<X^{\prime} \beta_{i}\right]=\Lambda\left(X^{\prime} \beta_{i}\right)
$$

On the other hand, the probit model is obtained when $F\left(X^{\prime} \beta_{i}\right)=\Phi\left(X^{\prime} \beta_{i}\right)$, that is the standard normal cumulative distribution function, such that the choice probability is given by:

$$
\operatorname{Pr}\left[-\left(\epsilon_{i 0}-\epsilon_{i 1}\right)<X^{\prime} \beta_{i}\right]=\Phi\left(X^{\prime} \beta_{i}\right)
$$

Household members are assumed to be rational and to make spending choices on the basis of observable characteristics such as (Head of household's education level, age, sex, marital status, place of residence, etc), which make up the $X$ vector in equations 4 and 5 , and are presented in the next section on table (1).

\section{Data and Analytical Strategy}

The empirical analysis is based upon data from the 2014 National Survey on Household Living Conditions(EICVM) administered by the National Institute for Statistics and demography (INSD) in Burkina faso. The broad objective of the EICVM survey is to provide information on households' living conditions at a given point in time, and more specifically to analyze poverty among those households. The survey uses a two-level stratified random sampling with weights that produce nationally representative estimates for households' per-capita annual spending on food and nonfood items, and a wide range of demographic and socioeconomic characteristics for the civilian, non 
institutionalized population in Burkina Faso. Primary sampling units are selected with probability proportional to their size, and the secondary sampling units or households selected with equal probability within those primary sampling units. The EICVM survey data is collected over a period of twelve months, our analysis includes a total of 10411 households after accounting for variables selection and missing data constraints.

\subsection{Dependent Variable Construction}

It is assumed that households as rational optimizers are looking to maximize utility from the consumption of goods and services they purchase annually. In this quest to satisfy their needs, households choose to spend yearly on consumption (for food and non-food items), amounts either greater than the poverty lines for both food and overall consumptions (in which cases the household experiences "food security" and "monetary security") or less than the poverty lines (in which cases the household experiences "food insecurity" and "monetary poverty") 1 . These suggest that households per-capita annual spending on food, as well as per-capita overall annual spending are respectively good indicators of households food insecurity status, and monetary poverty status. In this way, being characterized as "food secure", "monetary secure", "food insecure" or "monetary poor" is a deliberate choice of the household to spend or not annually per-capita, amounts "greater than the corresponding poverty lines" in the satisfaction of their needs. Given the 2014 food poverty line, and overall poverty line at 102,040 CFA and 153,530 CFA respectively, and the observed annual per-capita spending $y_{i}$, for $i=1,2$ (with $\mathrm{i}=1$ if spending on food consumption, and $\mathrm{i}=2$ if overall consumption spending) the binary dependent variables capturing households' food insecurity status, and monetary poverty status are given by :

$$
\text { FoodPovStat }=\left\{\begin{array}{l}
\text { Food Security }=1 \quad \forall \quad y_{1}>102,040, \\
\text { Food Insecurity }=0 \quad \forall \quad y_{1} \leq 102,040
\end{array}\right.
$$

and

$$
\text { MoneyPovStat }=\left\{\begin{array}{l}
\text { Monetary Security }=1 \quad \forall y_{2}>153,530, \\
\text { Monetary Poverty }=0 \quad \forall y_{2} \leq 153,530
\end{array}\right.
$$

If we further make the assumption that households as rational optimizers care first about their basic needs in relation to food consumption, before caring about the other relatively less essential needs. Then we can define a selection equation characterizing the incidence of food insecurity,

\footnotetext{
${ }^{1}$ This definition of Poverty status, is adopted by INSD in Burkina faso, which is the agency in charge of the EICVM survey. INSD identified the 2014 food poverty line at 102,040 CFA; and the overall poverty line at 153,530 CFA
} 
along with an outcome equation characterizing the incidence of monetary poverty subject to food insecurity. Together, this gives a bivariate probit model of food insecurity and monetary poverty (or food security and monetary security). This assumption is later on tested using the correlation coefficient between the processes describing food security and monetary security in Burkina Faso.

\subsection{Bivariate Probit Model of Education, Food Security and Monetary Security}

As the symmetrical representation of the bivariate model of food insecurity and monetary poverty, the bivariate model of food security and monetary security specifies a binary food security variable $\left(y_{1}\right)$ defining whether or not a household has spent an amount above the food poverty line, and a binary monetary security variable $\left(y_{2}\right)$ capturing whether or not a household has spent an amount above the overall poverty line. More specifically, if $y_{1}^{\star}$ is the latent utility characterizing the household's average propensity to spend above the food poverty line, while $y_{2}^{\star}$ is the latent utility characterizing the household's average propensity to spend above the overall poverty line, and educ the nominal variable characterizing the head of household's educational attainment. Then the bivariate model comprises the food security equation:

$$
y_{1}= \begin{cases}1 & \text { if } y_{1}^{\star}>0 \\ 0 & \text { if } y_{1}^{\star} \leq 0\end{cases}
$$

and the monetary security equation:

$$
y_{2}= \begin{cases}1 & \text { if } y_{2}^{\star}>0 \\ 0 & \text { if } y_{2}^{\star} \leq 0\end{cases}
$$

The bivariate system of additive random utilities can be written as,

$$
\left\{\begin{array}{l}
y_{1}^{\star}=\beta_{01} e d u c+x_{1}^{*} \beta_{1}+\epsilon_{1} \\
y_{2}^{\star}=\beta_{02} e d u c+x_{2}^{*} \beta_{2}+\epsilon_{2}
\end{array}\right.
$$

Where $\beta_{01}$ et $\beta_{02}$ represent the marginal effects of educational attainment on the household propensity to spend above the food poverty line, and the overall poverty line respectively. $x_{1}^{*}$ represents the vector of covariates in the food security equation; it has two component parts, a vector of nominal component variables $X_{11}^{\prime}$, and a vector of numerical component variables $X_{21}^{\prime}$. While $x_{2}^{*}$ represents the vector of covariates in the monetary security equation; with also two component parts, a vector of nominal component variables $X_{12}^{\prime}$, and a vector of numerical component variables $X_{22}^{\prime}$. Therefore equation 10 can be rewritten as:

$$
\left\{\begin{array}{l}
y_{1}^{\star}=\beta_{01} e d u c+X_{11}^{\prime} \beta_{11}+X_{21}^{\prime} \beta_{21}+\epsilon_{1} \\
y_{2}^{\star}=\beta_{02} e d u c+X_{12}^{\prime} \beta_{12}+X_{22}^{\prime} \beta_{22}+\epsilon_{2}
\end{array}\right.
$$


In this formulation, $\beta_{11}$ and $\beta_{12}$ represent the vectors of marginal effects from the nominal covariates in the food security equation, and the monetary security equation respectively. While $\beta_{21}$ and $\beta_{22}$ represent the vectors of marginal effects from the numerical co-variates in the food security equation, and the monetary security equation respectively. The challenge arises in identifying the coefficients when $\epsilon_{1}$ and $\epsilon_{2}$ are correlated. Estimation by maximum likelihood is straightforward if we make the additional assumption that the correlated errors are jointly normally distributed and homosckedastic, with

$$
\left(\begin{array}{l}
\epsilon_{1} \\
\epsilon_{2}
\end{array}\right) \sim N\left[\left(\begin{array}{l}
0 \\
0
\end{array}\right),\left(\begin{array}{cc}
1 & \sigma_{12} \\
\sigma_{12} & \sigma_{2}^{2}
\end{array}\right)\right]
$$

Where the normalization $\sigma_{1}^{2}=1$ is used for identification purposes. The standard in the literature when correlation exists is to use the two step estimator by Heckman (1979) to identify the system (Cameron and Trivedi, 2005, 547-548). In the current analysis, we relax the linearity assumption through semi-parametric estimation, by specifying general copula functions for the parametrically entering numerical variables in the system of equations, yielding:

$$
\left\{\begin{array}{l}
y_{1}^{\star}=\beta_{01} e d u c+X_{11}^{\prime} \beta_{11}+g\left(X_{21}^{\prime} \beta_{21}, \epsilon_{1}\right) \\
y_{2}^{\star}=\beta_{02} e d u c+X_{12}^{\prime} \beta_{12}+g\left(X_{22}^{\prime} \beta_{22}, \epsilon_{2}\right)
\end{array}\right.
$$

With the function $g($.$) unknown, the distribution of \left(\epsilon_{1}, \epsilon_{2}\right)$ is left unspecified. The model is called partially linear, and can be estimated using the semi-parametric methods presented in Wojtys et al. (2016).

\subsection{Independent Variables}

Like any scientific study using evidence from observational data, our interests here centers on a postulated causal influence from the attributes and environment of households' to their responses, or per-capita annual spending choices. It's assumed that these spending choices reflect households' food insecurity and monetary poverty status. As such, in choosing the variables to be included in the model, the question that needs to be addressed in conjunction with our proposed behavioral model is: what other factors affect households spending choices?

Keeping in mind that the primary goal of this empirical analysis is not to find the determinants of households' food insecurity and monetary poverty in Burkina Faso, but to measure the role that education play in reducing household food insecurity and monetary poverty, then our primary independent variable is the level of education of the head of household. In order to achieve the study goal hoverer we need to account for the effects of other covariates impacting this relationship (see equations 10, 11, 13) such as socio-demographic covariates ( marital status, sex, and age of heads of households). Table (1) provides definitions and summary statistics for all the independent variables in the analysis. 


\section{Results}

We first tested the association between variables using cross-tabulation and chi-square tests. The test is unilaterally one sided since the chi-square calculation generates only positive values, and is used to check the link between the two binary dependent variables and the nominal explanatory variables. With our primary interest in the effect of education in reducing household food insecurity and monetary poverty, the null hypothesis is that both household food insecurity and monetary poverty are independent of the head of household's education level, versus the alternative that they are dependent. The same test is repeated with the other nominal variables in the model, table(2), shows the results. The p-values of the test for all the variables are less than the $5 \%$ significance level, suggesting a dependence link between each nominal independent variable and the two binary dependent variables at a $95 \%$ confidence level.

Table(2) also presents descriptive results from our study sample. Focusing on the second column of the table, the descriptive results show that $84.6 \%$ of the households experiencing food insecurity in Burkina Faso do not have any formal education, $10.4 \%$ have primary education, $4.7 \%$ a secondary education, and only $0.3 \%$ have higher education. Similarly, female headed households represent $88.3 \%$ of those experiencing food insecurity, against only $11.7 \%$ for male headed households. In relation to marital status, the greatest share of households experiencing food insecurity in the country is found among households with married heads at $90.1 \%$, followed by those headed by widows at $7.7 \%$, and then by those headed by singles at $2.1 \%$. Finally in relation to residency status, households in rural areas experience relatively more food insecurity at $72.2 \%$, against $27.8 \%$ for those in urban areas.

Focusing now on the third column of table (2), we see that $89.8 \%$ of all the households experiencing monetary poverty in Burkina Faso do not have any formal education, $7.8 \%$ have primary education, $2.3 \%$ a secondary education, and less than $0.1 \%$ have higher education. Similarly, female headed households represents $88.5 \%$ of those experiencing monetary poverty, against $11.5 \%$ for male headed households. In relation to marital status, the greatest share of households experiencing monetary poverty in the country is found among households with married heads at 90.6\%, followed by those headed by widows at $7.5 \%$, and then those headed by singles at $1.9 \%$. Finally in relation to residency status, households in rural areas experience more monetary poverty at $79.9 \%$, against $20.1 \%$ for those in urban areas. Overall the relative frequency results point out the importance of heads of households educational attainment for both households' food security and monetary/financial security in burkina faso.

In our quest to test the three hypothesis initially formulated in the introduction, we've specified and estimated three models: (i) a multivariate probit model with results shown in the second column of table(3), (ii) a multivariate logit model with results shown in the third column of table(3), and (iii) two bivariate probit (fully parametric and semi-parametric) models with results shown in table (5). In the first two specifications (probit and logit) the implicit assumption is 
that household food insecurity and monetary poverty are described by two independent processes. This assumption is relaxed in the two bivariate specifications so as to test our third formulated hypothesis regarding the independence between these two processes.

\subsection{The Uni-variate effect of Educational attainment on Food Security}

The single equation probit and logit results of the effects of educational attainment on food security are presented in table(3) for the direct effects, and table(4) for the marginal effects and odds ratios. These results allow us to test the first hypothesis (H1), stating " no significant difference between households with formally educated heads and those with uneducated heads in their experience of food insecurity in Burkina Faso". In light of both probit and logit results we can confidently reject this null hypothesis, and conclude that the evidence is enough to suggest the existence of a significant difference between households with formally educated heads and those with uneducated heads in their experience of food insecurity in Burkina Faso.

In fact, the results show positive and significant relative effects of primary, secondary, and higher education, compared to no education, in households likelihood of food security in burkina faso. These suggest therefore that compared to households headed by someone with no education, those headed by someone with a primary, secondary and higher education are more likely to achieve food security. This higher relative likelihood of achieving food security increases with increasing levels of achieved education. This observation is validated by both probit and logit representations, showing its robustness to model specification. Considering the model selection of AIC and BIC, we could say that logit and probit models have fairly similar performances in describing household food security in burkina faso, although the probit model does have slighly lower values of the AIC $(11758.0<11758.2)$ and the $\mathrm{BIC}(11859.5<11859.7)$. The resulting marginal effects, and odds ratio in table (4) confirm the outcome of this first hypothesis test (H1).

The marginal effects in the second column under food security show indeed that households for which the head already has a primary education, a one level increase in the head of household education leads to an $8.3 \%$ increase in the household likelihood of achieving food security. This increased probability of achieving food security is $20.2 \%$ and $43.1 \%$ respectively for households with secondary and higher educated heads. Hence suggesting that education does have positive and increasing marginal effects on the probability of achieving food security in burkina faso. The odds ratios in the third column under food security suggest that compared to households where the head has no education, those headed by someone with a primary, secondary, and higher education have respectively 1.40 times, 2.27 times, and 8.17 times more chances of achieving food security in Burkina Faso.

\subsection{The Uni-variate effect of Educational attainment on Monetary Security}

The single equation probit and logit results of the effects of educational attainment on monetary poverty are presented in table $(3)$ for the direct effects, and table $(4)$ for the marginal effects and 
odds ratios. These results allow us to test the second hypothesis (H2), stating " no significant difference between households with formally educated heads and those with uneducated heads in their experience of monetary poverty in Burkina Faso". In light of both probit and logit results we can confidently reject this null hypothesis, and conclude that the evidence is enough to suggest the existence of a significant difference between households with formally educated heads and those with uneducated heads in their experience of monetary poverty in Burkina Faso.

In fact, the results show positive and significant relative effects of primary, secondary, and higher education, compared to no education, in households likelihood of monetary poverty in burkina faso. These suggest therefore that compared to households headed by someone with no education, those headed by someone with a primary, secondary or higher education are more likely to achieve monetary security. This higher relative likelihood of achieving monetary security increases with increasing levels of achieved education. This observation is validated by both probit and logit representations, showing its robustness to model specification. Considering the model selection criterion of AIC and BIC, we could say that logit and probit models also have fairly similar performances in describing household monetary poverty in burkina faso, although the probit model have slightly lower values of the AIC $(11155.5<11169.4)$ and the $\mathrm{BIC}(11257.0<11270.9)$. The resulting marginal effects, and odds ratio in table(4) confirm the outcome of this second hypothesis test $(\mathrm{H} 2)$.

The marginal effects in the second column under "monetary security" show indeed that households for which the head already has a primary education, a one level increase in the head of household education leads to a $12.6 \%$ increase in the household likelihood of achieving monetary security. This increased probability of achieving monetary security is $23.3 \%$ and $33.7 \%$ respectively for households with secondary and higher educated heads. Hence suggesting that education does also have positive and increasing marginal effects on the probability of achieving monetary security in burkina faso. The odds ratios in the third column under "monetary security" suggest that compared to households for which the head has no education, those headed by someone with a primary, secondary, and higher education have respectively 1.87 times, 3.78 times, and 33.73 times more chances of achieving monetary security in Burkina Faso.

\subsection{The fully-parametric and semi-parametric bi-variate probit results}

The bivariate probit (fully parametric in equations (10) and (11) and semi-parametric in equation (13) specifications relax the implicit assumption by single equation probit and logit models, that household food insecurity and monetary poverty are described by two independent processes. They are therefore intended to test the third formulated hypothesis (H3), stating " the independence between households' food insecurity and monetary poverty in Burkina Faso".

The results from the bivariate specifications are presented in table(5). They show that the unobserved factors affecting households' average propensity to spend above the food poverty line 
(or achieving food security), are positively correlated with the unobserved factors affecting the household average propensity to spend above the overall poverty line (or achieving monetary security). This is true for both, the fully parametric specification with $\hat{\theta}=0.931$, and the semi-parametric bivariate specification with $\hat{\theta}=0.927$. These $\hat{\theta}$ correlation coefficients are both statistically significant as shown by their respective $95 \%$ confidence intervals $(0.921,0.94)$ and $(0.918,0.937)$ in table (5). Therefore we reject the null hypothesis (H3), and conclude that the evidence strongly suggest a positive dependence between households' food insecurity and monetary poverty in Burkina Faso.

The outcome of this third hypothesis test, further suggests that the initial implicit independence assumption by the single equation multivariate probit and logit specifications is not valid, as such the bivariate (parametric and semi-parametric) specifications of these two processes can better capture the true effects of a head of household education on the household food insecurity and monetary poverty in Burkina Faso. Focusing on the AIC and BIC criterion for the bivariate probit specifications presented in table (5), the semi-parametric model with relatively smaller values of $(\mathrm{AIC}=18722.06$, and $\mathrm{BIC}=19024.09)$ is preferred to the fully parametric specification with (AIC $=19162.41$, and $\mathrm{BIC}=19314.68)$. This suggests that relaxing the linearity assumption for the head of household age, and household size variables, in addition to relaxing the independence assumption between food insecurity and monetary poverty, provides for the best model specification among all the presented specifications. Furthermore, for this preferred model, the convergence diagnostic checks for the trust region iteration algorithm (see (Wojtys et al. 2016) ) used to identify the parameters of the model, shows satisfactory convergence as the largest absolute gradient value (1.856591e-08) is close to zero, and the observed information matrix is positive definite.

\subsubsection{The bivariate effects of educational attainment on food security and monetary security}

Focusing on the semi-parametric bivariate results in the third column of table (5), it can be noted that a head of household educational attainment has positive effects on both household food security and monetary security as previously observed with the single equation multivariate probit and logit specifications. More specifically, compared to households headed by someone with no education, those headed by someone with a primary, secondary or higher education are respectively $19.8 \%, 49.7 \%$ and $118.9 \%$ more likely to achieve food security, and respectively $40.1 \%, 77.0 \%$ and $172.3 \%$ more likely to achieve monetary security. From this, the previous conclusions reached for hypotheses $\mathrm{H} 1$ and $\mathrm{H} 2$ are once more confirmed. Therefore we can safely conclude that the evidence strongly suggests a significant difference between households with formally educated heads and those with uneducated heads in their experience of food insecurity and monetary poverty.

\subsection{The bi-variate effects of the other control variables on food security and monetary security}

Although our aim is not to model the effects of all determinants of food insecurity and monetary poverty in Burkina Faso, but to understand the role played by heads of households' education, its important to note that other factors do significantly affect households' food insecurity and 
monetary poverty in the country. Focusing on the food security equation in our preferred semiparametric model, the results presented in the third column of table (5) show that the variables (female and rural) which enter the model parametrically, are statistically significant at the $5 \%$ level. In fact, we see that compared to households headed by males, those headed by females have respectively $16.1 \%$ and $24.7 \%$ less chances of achieving food security and overall monetary security. Similarly, compared to households living in urban areas, those living in rural areas have respectively $38.9 \%$ and $63 \%$ less chances of achieving food security and overall monetary security.

Now turning to the smoothed terms for the head of household's "age" and household size "hhsize" variables in the food security and monetary security equations of the semi-parametric bivariate probit model, the p-values $(<0.05)$ and estimated degrees of freedoms (edf) in the third column of table (5) indicate that the age of a head of household, and the household size do have significant impacts on household food insecurity and monetary poverty. As shown by the respective smooth functions estimates and $95 \%$ confidence bands in figure(1) for food security and figure(2) for overall monetary security, these effects are fairly convex for age, and concave for household size. These results further suggest that at lower head of household age values $(<35)$, aging contributes to increasing the chances of household food security, however, at higher age values ( $>35)$, aging reduces the chances of household food security. On the other hand, in the reasonable range of household size $(<20)$, an increase in household size by one more member reduces the likelihood of both food security and monetary security, as both smooth functions decrease in that range.

\section{Discussions and Conclusion}

Our analysis has concerned itself with analyzing the effects of heads of households educational attainment on households' food security and monetary poverty in Burkina Faso. In the study design, we embraced a more focused and contemporaneous definition of food insecurity which allowed us to characterize household level heterogeneity in food security, using households "willingness and ability" to spend annually on food consumption a per-capita amount above the food poverty line of 102,040 CFA franc, while "monetary poverty" was defined as households "unwillingness or inability" to spend above the overall poverty line of 153,530 CFA franc. Using an extended Random Utility model to explain households spending choices and poverty status, both multivariate logit and probit specifications were implemented for the choice probabilities. Furthermore, relaxing the implicit independence assumption of the single equation multivariate logit and probit specifications, the bivariate probit models with both fully parametric and semi-parametric specifications were also implemented to describe food insecurity and monetary poverty.

Based on the results as presented in the previous section, along with other factors, a head of household educational attainment was found to be an important determinant of household food insecurity and monetary poverty. Although less attention had been given to this role of education in the economics literature, this study validated the need to use education as a sustainable strategy 
for fighting against food insecurity and monetary poverty in Burkina Faso, and more generally in sub-Saharan Africa. The results are not only in line with global commitments through the Incheon Declaration of the "Education 2030" agenda, adopted at the World Education Forum in May 2015 (Declaration, 2015), but are also consistent with human capital theory predictions, which stipulates that education affects positively economic outcomes through its effect on productivity. This imply that we could possibly decompose the observed effects of education on food security into two types of effects: (i) A supply side productivity effect: through which, highly educated family heads by being more productive can achieve greater quantity of food production, and thereby reduce the insecurity linked to food shortage; and (ii) A demand side purchasing power effect: trough which families with highly educated heads can benefit from greater purchasing power in terms of real income to acquire food, even under overall food shortage/insecurity.

These results also allow us to make the following recommendations so as to further reduce the incidence of food insecurity and monetary poverty among households in Burkina Faso: (i) Improving the conditions for access, quality, and the reduction of regional and gender disparities in the education sector by carrying out social protection actions to encourage the education of children especially that of girls in rural areas; (ii) Making education compulsory and accessible up to the higher education level, and encourage schooling of children from disadvantaged background through scholarships; (iii) Sensitizing households members to consider marriage and child bearing only after completion of the compulsory education through usage of family planing and contraceptives.

Like any empirical analysis however, this study is not exempt of limitations. For example (i) only one dimensional food insecurity and monetary poverty measures have been considered in the analysis, which can slightly limit the strength of our conclusions; also (ii) despite being relatively up to date compared to its 2009 version, the 2014 EICVM survey only allows us to characterize cross-sectional effects, and therefore does not take into account the dynamics of food insecurity and monetary poverty overtime. Despite these minor limitations however, the results and recommendations from this study could safely pave the ground for the practical implementation of "Education 2030" for Burkina Faso. 
Table 1: Summary Description of the Variables used in the Econometric Modeling

\begin{tabular}{|c|c|c|c|}
\hline $\begin{array}{l}\text { Sample Size } \\
\text { Overall Poverty line } \\
\text { Food Poverty line }\end{array}$ & $\begin{array}{l}n_{2014} \\
\text { in CFA francs } \\
\text { in CFA francs }\end{array}$ & $\begin{array}{c}10,411 \\
153,530 \\
102,040\end{array}$ & \\
\hline & & Mean & sd \\
\hline $\begin{array}{l}\text { CapSpendg } \\
\text { CapSpendgF } \\
\text { Age } \\
\text { HHsize }\end{array}$ & $\begin{array}{l}\text { Per-capita overall spending in FCA Franc } \\
\text { Per-capita spending on food in FCA Franc } \\
\text { age in years of the head of household } \\
\text { number of people in the household }\end{array}$ & $\begin{array}{c}273000 \\
137900 \\
46.57 \\
7.48 \\
\end{array}$ & $\begin{array}{c}309366.8 \\
164633.5 \\
15.52 \\
4.97 \\
\end{array}$ \\
\hline $\begin{array}{l}\text { Food Poverty Status } \\
\text { Food Security } \\
\text { Food Insecurity } \\
\text { Monetary Poverty Status } \\
\text { Monetary Security } \\
\text { Monetary Poverty } \\
\text { Education Level } \\
\text { None } \\
\text { Primary } \\
\text { Secondary } \\
\text { Higher } \\
\text { Sex } \\
\text { Female } \\
\text { Male } \\
\text { Marital Status } \\
\text { Single } \\
\text { Married } \\
\text { Widow } \\
\text { Residency Status } \\
\text { Rural } \\
\text { Urban }\end{array}$ & $\begin{array}{l}=1 \text { if household experiences food security } \\
=1 \text { if household experiences food Insecurity } \\
=1 \text { if household experiences monetary security } \\
=1 \text { if household experiences monetary poverty } \\
=1 \text { if head has no education } \\
=1 \text { if head has only a primary education } \\
=1 \text { if head has only a secondary education } \\
=1 \text { if head has some higher education } \\
=1 \text { if head of household is Female } \\
=1 \text { if head of household is Male } \\
=1 \text { if head of household is single } \\
=1 \text { if head of household is married } \\
=1 \text { if head of household is a widow } \\
=1 \text { if Household lives in Rural area } \\
=1 \text { if Household lives in Urban area }\end{array}$ & $\begin{array}{c}\text { Abs. Freq. } \\
\\
4628 \\
5783 \\
\\
6330 \\
4081 \\
\\
7782 \\
1273 \\
1087 \\
269 \\
\\
1389 \\
9022 \\
\\
586 \\
9011 \\
814 \\
6408 \\
4003\end{array}$ & \\
\hline
\end{tabular}

Source: The National Survey on Household Living Conditions(EICVM, 2014) 
Table 2: Chi-Squared test of Independence between the dependent variables and the nominal independent variables

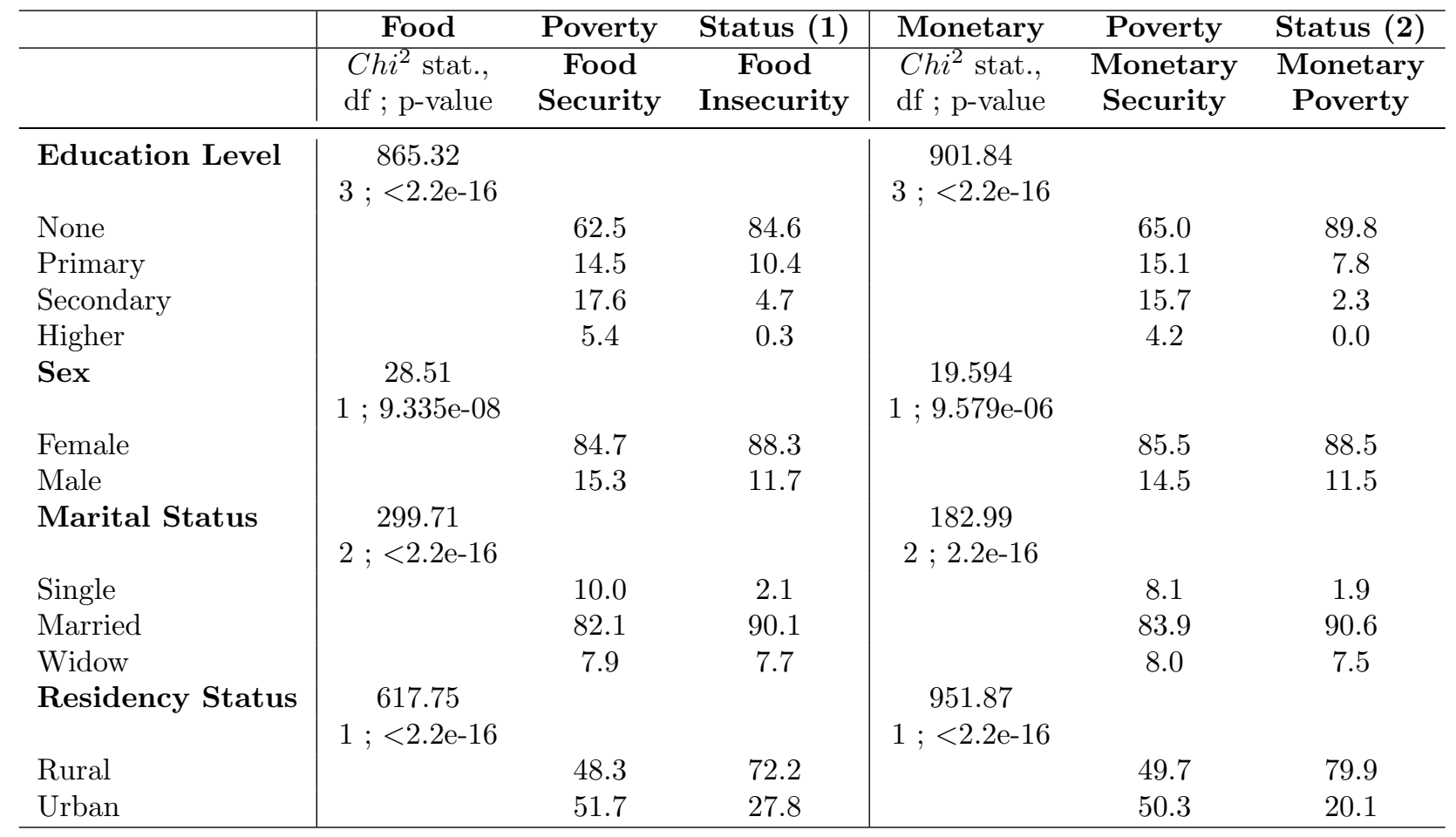


Table 3: Estimates of the Probit and Logit models for Food Security and Monetary Poverty in 2014

\begin{tabular}{|c|c|c|c|c|}
\hline & $\begin{array}{l}\text { Probit (1) } \\
\text { Food Security }\end{array}$ & Monetary Security & $\begin{array}{c}\text { Logit (2) } \\
\text { Food Security }\end{array}$ & Monetary Security \\
\hline (Intercept) & $\begin{array}{l}1.270^{* * *} \\
(0.109)^{\dagger}\end{array}$ & $\begin{array}{c}1.835^{* * *} \\
(0.123)\end{array}$ & $\begin{array}{c}2.129^{* * *} \\
(0.188)\end{array}$ & $\begin{array}{c}3.167^{* * *} \\
(0.219)\end{array}$ \\
\hline primary & $\begin{array}{c}0.203^{* * *} \\
(0.042)\end{array}$ & $\begin{array}{c}0.380^{* * *} \\
(0.045)\end{array}$ & $\begin{array}{c}0.335^{* * *} \\
(0.068)\end{array}$ & $\begin{array}{c}0.624^{* * *} \\
(0.076)\end{array}$ \\
\hline secondary & $\begin{array}{c}0.491^{* * *} \\
(0.050)\end{array}$ & $\begin{array}{c}0.757^{* * *} \\
(0.064)\end{array}$ & $\begin{array}{c}0.821^{* * *} \\
(0.084)\end{array}$ & $\begin{array}{c}1.330^{* * *} \\
(0.119)\end{array}$ \\
\hline higher & $\begin{array}{c}1.188^{* * *} \\
(0.129)\end{array}$ & $\begin{array}{c}1.707^{* * *} \\
(0.288)\end{array}$ & $\begin{array}{c}2.100^{* * *} \\
(0.249)\end{array}$ & $\begin{array}{c}3.518^{* * *} \\
(0.715)\end{array}$ \\
\hline female & $\begin{array}{c}-0.147^{* *} \\
(0.051)\end{array}$ & $\begin{array}{c}-0.228^{* * *} \\
(0.055)\end{array}$ & $\begin{array}{c}-0.240^{* *} \\
(0.086)\end{array}$ & $\begin{array}{c}-0.384^{* * *} \\
(0.093)\end{array}$ \\
\hline married & $\begin{array}{l}-0.097 \\
(0.074)\end{array}$ & $\begin{array}{c}0.074 \\
(0.086)\end{array}$ & $\begin{array}{l}-0.153 \\
(0.127)\end{array}$ & $\begin{array}{c}0.089 \\
(0.152)\end{array}$ \\
\hline widow & $\begin{array}{l}-0.238^{*} \\
(0.093)\end{array}$ & $\begin{array}{c}0.001 \\
(0.103)\end{array}$ & $\begin{array}{l}-0.399^{*} \\
(0.157)\end{array}$ & $\begin{array}{l}-0.038 \\
(0.180)\end{array}$ \\
\hline rural & $\begin{array}{c}-0.380^{* * *} \\
(0.030)\end{array}$ & $\begin{array}{c}-0.618^{* * *} \\
(0.031)\end{array}$ & $\begin{array}{c}-0.625^{* * *} \\
(0.049)\end{array}$ & $\begin{array}{c}-1.035^{* * *} \\
(0.053)\end{array}$ \\
\hline bs(hage) 1 & $\begin{array}{c}0.172 \\
(0.270)\end{array}$ & $\begin{array}{l}-0.255 \\
(0.285)\end{array}$ & $\begin{array}{c}0.223 \\
(0.459)\end{array}$ & $\begin{array}{l}-0.604 \\
(0.488)\end{array}$ \\
\hline bs(hage) 2 & $\begin{array}{l}-0.113 \\
(0.169)\end{array}$ & $\begin{array}{c}0.095 \\
(0.168)\end{array}$ & $\begin{array}{l}-0.179 \\
(0.286)\end{array}$ & $\begin{array}{c}0.174 \\
(0.282)\end{array}$ \\
\hline bs(hage) 3 & $\begin{array}{l}-0.262 \\
(0.258)\end{array}$ & $\begin{array}{c}-0.693^{* *} \\
(0.260)\end{array}$ & $\begin{array}{l}-0.482 \\
(0.439)\end{array}$ & $\begin{array}{c}-1.263^{* *} \\
(0.441)\end{array}$ \\
\hline bs(hhsize)1 & $\begin{array}{c}-5.683^{* * *} \\
(0.245)\end{array}$ & $\begin{array}{c}-5.347^{* * *} \\
(0.255)\end{array}$ & $\begin{array}{c}-9.526^{* * *} \\
(0.467)\end{array}$ & $\begin{array}{c}-8.969^{* * *} \\
(0.476)\end{array}$ \\
\hline bs(hhsize $) 2$ & $\begin{array}{c}2.741^{* * *} \\
(0.595)\end{array}$ & $\begin{array}{c}2.092^{\text {*** }} \\
(0.572)\end{array}$ & $\begin{array}{c}4.967^{* * *} \\
(1.340)\end{array}$ & $\begin{array}{c}3.966^{* * *} \\
(1.201)\end{array}$ \\
\hline bs(hhsize $) 3$ & $\begin{array}{c}-3.508^{* * *} \\
(1.025)\end{array}$ & $\begin{array}{c}-3.432^{* * *} \\
(1.002)\end{array}$ & $\begin{array}{c}-7.369^{* *} \\
(2.838)\end{array}$ & $\begin{array}{c}-6.918^{* *} \\
(2.523)\end{array}$ \\
\hline $\mathrm{AIC}$ & 11758.0 & 11155.5 & 11758.2 & 11169.4 \\
\hline $\mathrm{BIC}$ & 11859.5 & 11257.0 & 11859.7 & 11270.9 \\
\hline Log Likelihood & -5865.0 & -5563.7 & -5865.1 & -5570.7 \\
\hline Num. obs. & 10411 & 10411 & 10411 & 10411 \\
\hline
\end{tabular}

$\dagger$ standard deviation of the parameters in parentheses.

${ }^{* * *}$ Is the $0.01 \%$ significance level, ${ }^{* *}$ Is the $1 \%$ significance level, ${ }^{*}$ Is the $5 \%$ significance level. 
Table 4: Marginal Effects and Odds Ratios for the Logit models of Food Security and Monetary Poverty in 2014

\begin{tabular}{|c|c|c|c|c|}
\hline & $\begin{array}{l}\text { Marginal Effects } \\
\text { Food Security }\end{array}$ & $\begin{array}{c}\text { (M.E.) } \\
\text { Monetary Security }\end{array}$ & $\begin{array}{l}\text { Odds Ratios } \\
\text { Food Security }\end{array}$ & $\begin{array}{c}\text { (O.R.) } \\
\text { Monetary Security }\end{array}$ \\
\hline primary & $\begin{array}{c}0.083^{* * *} \\
(0.017)\end{array}$ & $\begin{array}{c}0.126^{* * *} \\
(0.014)\end{array}$ & $\begin{array}{c}1.398^{* * *} \\
(0.058)\end{array}$ & $\begin{array}{c}1.866^{* * *} \\
(0.141)\end{array}$ \\
\hline secondary & $\begin{array}{c}0.202^{* * *} \\
(0.020)\end{array}$ & $\begin{array}{c}0.233^{* * *} \\
(0.015)\end{array}$ & $\begin{array}{c}2.272^{* * *} \\
(0.059)\end{array}$ & $\begin{array}{c}3.781^{* * *} \\
(0.450)\end{array}$ \\
\hline higher & $\begin{array}{c}0.431^{* * *} \\
(0.030)\end{array}$ & $\begin{array}{l}0.337^{* * *} \\
(0.013)\end{array}$ & $\begin{array}{c}8.165^{* * *} \\
(2.037)\end{array}$ & $\begin{array}{c}33.730^{* * *} \\
(24.104)\end{array}$ \\
\hline female & $\begin{array}{c}-0.058^{* *} \\
(0.021)\end{array}$ & $\begin{array}{c}-0.089^{* * *} \\
(0.022)\end{array}$ & $\begin{array}{c}0.787^{* * *} \\
(0.067)\end{array}$ & $\begin{array}{c}0.681^{* * *} \\
(0.063)\end{array}$ \\
\hline married & $\begin{array}{c}-0.038 \\
(0.032)\end{array}$ & $\begin{array}{c}0.020 \\
(0.034)\end{array}$ & $\begin{array}{l}0.858 \\
(0.109)\end{array}$ & $\begin{array}{l}1.093 \\
(0.166)\end{array}$ \\
\hline widow & $\begin{array}{c}-0.096^{* *} \\
(0.036)\end{array}$ & $\begin{array}{l}-0.008 \\
(0.040)\end{array}$ & $\begin{array}{l}0.671^{*} \\
(0.105)\end{array}$ & $\begin{array}{c}0.963 \\
(0.173)\end{array}$ \\
\hline rural & $\begin{array}{c}-0.154^{* * *} \\
(0.012)\end{array}$ & $\begin{array}{c}-0.217^{* * *} \\
(0.010)\end{array}$ & $\begin{array}{c}0.535^{* * *} \\
(0.026)\end{array}$ & $\begin{array}{c}0.355^{* * *} \\
(0.019)\end{array}$ \\
\hline bs(hage)1 & $\begin{array}{c}0.055 \\
(0.113)\end{array}$ & $\begin{array}{c}-0.134 \\
(0.108)\end{array}$ & $\begin{array}{c}1.249 \\
(0.573)\end{array}$ & $\begin{array}{c}0.547 \\
(0.267)\end{array}$ \\
\hline bs(hage) 2 & $\begin{array}{c}-0.044^{* * *} \\
(0.071)\end{array}$ & $\begin{array}{c}0.039 \\
(0.063)\end{array}$ & $\begin{array}{c}0.836 \\
(0.239)\end{array}$ & $\begin{array}{l}1.190 \\
(0.355)\end{array}$ \\
\hline bs(hage) 3 & $\begin{array}{l}-0.119 \\
(0.108)\end{array}$ & $\begin{array}{c}-0.280^{* *} \\
(0.098)\end{array}$ & $\begin{array}{c}0.618 \\
(0.271)\end{array}$ & $\begin{array}{l}0.283^{* *} \\
(0.125)\end{array}$ \\
\hline bs(hhsize) 1 & $\begin{array}{c}-2.350^{* * *} \\
(0.116)\end{array}$ & $\begin{array}{c}-1.991^{* * *} \\
(0.104)\end{array}$ & $\begin{array}{c}0.00007^{* * *} \\
(0.00005)\end{array}$ & $\begin{array}{l}0.0001^{* * *} \\
(0.00006)\end{array}$ \\
\hline bs(hhsize)2 & $\begin{array}{c}1.225^{* * *} \\
(0.331)\end{array}$ & $\begin{array}{c}0.880^{* * *} \\
(0.266)\end{array}$ & $\begin{array}{c}143.64^{* * *} \\
(0.019)\end{array}$ & $\begin{array}{c}52.787^{* * *} \\
(63.375)\end{array}$ \\
\hline bs(hhsize) 3 & $\begin{array}{c}-1.817^{* *} \\
(0.700)\end{array}$ & $\begin{array}{c}-1.536^{* *} \\
(0.004)\end{array}$ & $\begin{array}{c}0.0006^{* *} \\
(0.002)\end{array}$ & $\begin{array}{l}0.001^{* *} \\
(0.002)\end{array}$ \\
\hline
\end{tabular}

${ }^{* * *}$ Is the $0.01 \%$ significance level, ${ }^{* *}$ Is the $1 \%$ significance level, ${ }^{*}$ Is the $5 \%$ significance level. $\dagger$ standard deviation of the parameters in parentheses. 
Table 5: (Semi)parametric bivariate probit models of Food Security and Monetary Poverty in 2014

\begin{tabular}{|c|c|c|c|c|}
\hline & $\begin{array}{c}\text { Fully-Parametric } \\
\text { Food Security }\end{array}$ & $\begin{array}{l}\text { Bivariate Model } \\
\text { Monetary Security }\end{array}$ & $\begin{array}{l}\text { Semi-Parametric } \\
\text { Food Security }\end{array}$ & $\begin{array}{l}\text { Bivariate Model } \\
\text { Monetary Security }\end{array}$ \\
\hline (Intercept) & $\begin{array}{l}1.113^{* * *} \\
(0.079)^{\dagger}\end{array}$ & $\begin{array}{c}1.598^{* * *} \\
(0.089)\end{array}$ & $\begin{array}{c}0.111^{* * *} \\
(0.077)\end{array}$ & $\begin{array}{c}0.631^{* * *} \\
(0.119)\end{array}$ \\
\hline primary & $\begin{array}{c}0.202^{* * *} \\
(0.041)\end{array}$ & $\begin{array}{c}0.399^{* * *} \\
(0.044)\end{array}$ & $\begin{array}{c}0.198^{* * *} \\
(0.042)\end{array}$ & $\begin{array}{c}0.401^{* * *} \\
(0.045)\end{array}$ \\
\hline secondary & $\begin{array}{c}0.544^{* * *} \\
(0.049)\end{array}$ & $\begin{array}{c}1.794^{* * *} \\
(0.061)\end{array}$ & $\begin{array}{c}0.497^{* * *} \\
(0.050)\end{array}$ & $\begin{array}{c}0.770^{* * *} \\
(0.063)\end{array}$ \\
\hline higher & $\begin{array}{c}1.256^{* * *} \\
(0.125)\end{array}$ & $\begin{array}{c}1.142^{* * *} \\
(0.282)\end{array}$ & $\begin{array}{l}1.189^{* * *} \\
(0.129)\end{array}$ & $\begin{array}{c}1.723^{* * *} \\
(0.285)\end{array}$ \\
\hline female & $\begin{array}{l}-0.050 \\
(00.051)\end{array}$ & $\begin{array}{l}-0.112^{*} \\
(0.053)\end{array}$ & $\begin{array}{c}-0.161^{* *} \\
(0.052)\end{array}$ & $\begin{array}{c}-0.247^{* * *} \\
(0.055)\end{array}$ \\
\hline married & $\begin{array}{c}-0.290^{* * *} \\
(0.069)\end{array}$ & $\begin{array}{l}-0.147 \\
(0.079)\end{array}$ & $\begin{array}{l}-0.081 \\
(0.076)\end{array}$ & $\begin{array}{c}0.041 \\
(0.086)\end{array}$ \\
\hline widow & $\begin{array}{c}-0.338^{* * *} \\
(0.088)\end{array}$ & $\begin{array}{l}-0.144 \\
(0.097)\end{array}$ & $\begin{array}{l}-0.223^{*} \\
(0.094)\end{array}$ & $\begin{array}{l}-0.038 \\
(0.103)\end{array}$ \\
\hline rural & $\begin{array}{c}-0.378^{* * *} \\
(0.029)\end{array}$ & $\begin{array}{c}-0.610^{* * *} \\
(0.030)\end{array}$ & $\begin{array}{c}-0.389^{* * *} \\
(0.030)\end{array}$ & $\begin{array}{c}-0.630^{* * *} \\
(0.031)\end{array}$ \\
\hline age & $\begin{array}{c}-0.004^{* * *} \\
(0.001)\end{array}$ & $\begin{array}{c}-0.004^{* * *} \\
(0.001)\end{array}$ & $\begin{array}{c}\mathrm{p} \text {-val }=494 \mathrm{e}-6^{* * *} \\
(\mathrm{edf}=6.482)\end{array}$ & $\begin{array}{c}\mathrm{p} \text {-val }=261 \mathrm{e}-6^{* * *} \\
(\mathrm{edf}=5.983)\end{array}$ \\
\hline hhsize & $\begin{array}{c}-0.092^{* * *} \\
(0.004)\end{array}$ & $\begin{array}{c}-0.091^{* * *} \\
(0.003)\end{array}$ & $\begin{array}{c}\text { p-val <2e- } 16^{* * *} \\
(\text { edf }=6.173)\end{array}$ & $\begin{array}{l}\text { p-val }<2 \mathrm{e}-16^{* * *} \\
(\text { edf }=6.018)\end{array}$ \\
\hline$\hat{\tau}$ & & $\begin{array}{c}0.762 \\
(0.745,0.777)^{\dagger \dagger}\end{array}$ & & $\begin{array}{c}0.756 \\
(0.74,0.772)\end{array}$ \\
\hline$\hat{\theta}$ & & $\begin{array}{c}0.931 \\
(0.921,0.94)\end{array}$ & & $\begin{array}{c}0.927 \\
(0.918,0.937)\end{array}$ \\
\hline AIC & & 19162.41 & & 18722.06 \\
\hline BIC & & 19314.68 & & 19024.09 \\
\hline
\end{tabular}

*** Is the $0.01 \%$ significance level, ${ }^{* *}$ Is the $1 \%$ significance level, ${ }^{*}$ Is the $5 \%$ significance level.

$\dagger$ standard deviation of the parameters in parentheses.

†† The $95 \%$ confidence intervals on tau and theta 

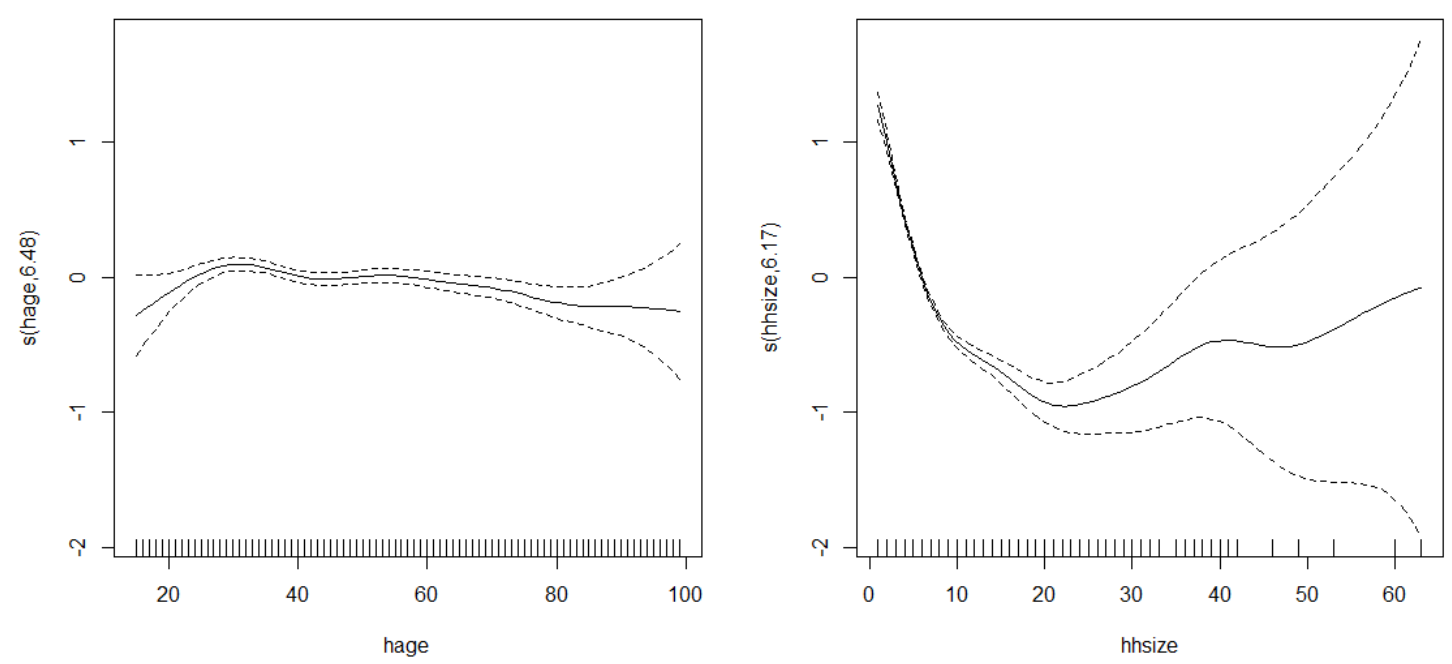

Figure 1: Smooth function estimates and 95\% confidence bands for the numerical variables in the food security equation
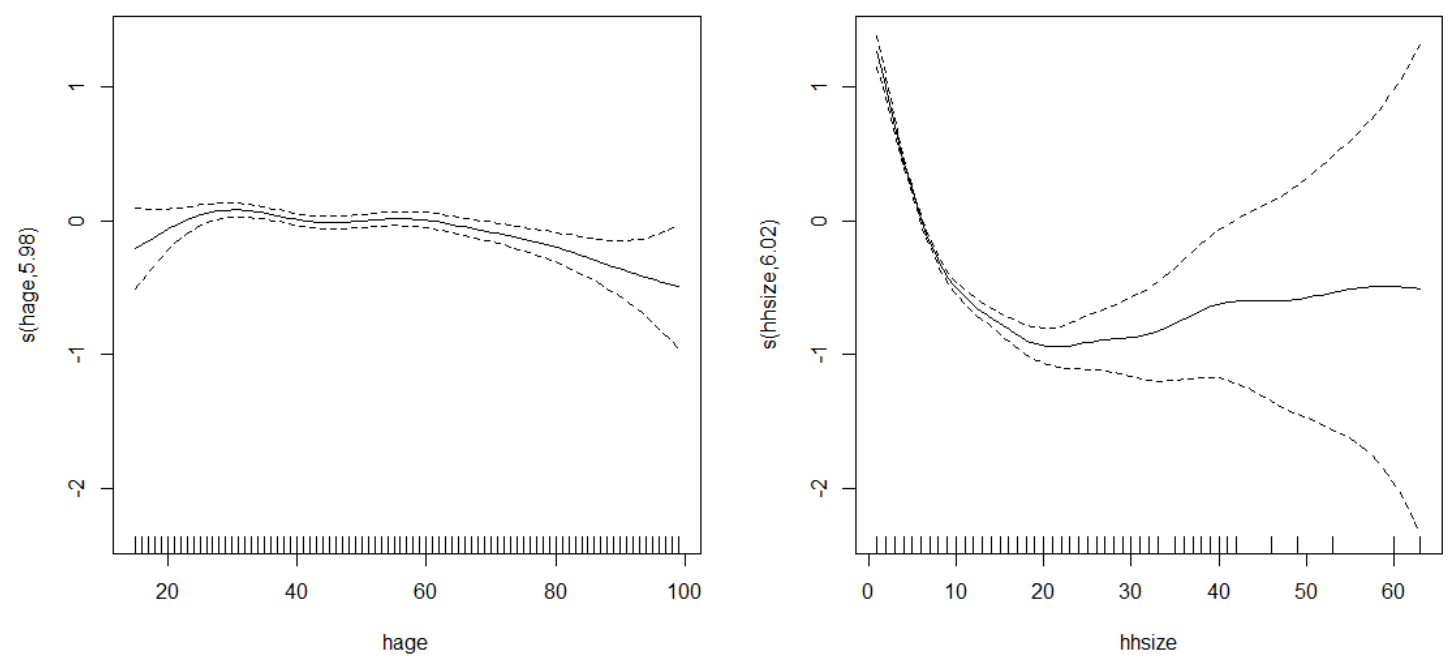

Figure 2: Smooth function estimates and $95 \%$ confidence bands for the numerical variables in the monetary security equation 


\section{References}

Altman, Miriam, Tim Hart and Peter Jacobs (2009), 'Household food security status in south africa', Agrekon 48(4), 345-361.

Bremner, Jason (2012), 'Population and food security: Africa's challenge', Population Reference Bureau Policy Brief.

Cameron, A Colin and Pravin K Trivedi (2005), Microeconometrics: methods and applications, Cambridge university press.

Coates, Jennifer, Edward A Frongillo, Beatrice Lorge Rogers, Patrick Webb, Parke E Wilde and Robert Houser (2006), 'Commonalities in the experience of household food insecurity across cultures: what are measures missing?', The Journal of nutrition 136(5), 1438S-1448S.

Declaration, Incheon (2015), Education 2030: Towards inclusive and equitable quality education and lifelong learning for all, in 'World Education Forum'.

Ehui, Simeon (2002), Food security in sub-Saharan Africa to 2020, number 49, ILRI (aka ILCA and ILRAD).

FARA, INERA, ZEF (2015), Potentials and possibilities for german collaboration in agriculture - burkina faso, Report 23p, Program of Accompanying Research for Agricultural Innovation (PARI), and the German Federal Ministry of Economic Cooperation and Development(BMZ).

GARRIDO, ELIA SÁNCHEZ and ISABEL SUÁREZ SÁNCHEZ (2015), 'Protection sociale et sécurité alimentaire au burkina faso', Les Cantines Scolaires. $46 p$.

Heckman, James J. (1979), 'Sample selection bias as specification error', Econometrica 47(1), 153161.

IFAD (2012), Burkina faso accelarating progress towards the mdgs, eradicate extreme poverty and hunger, Report 53p, The International Fund for Agricultural Development (IFAD).

INSD (2015), Rapport enquete multisectorielle continue (emc) 2014: Profil de pauvreté et d'inégalités, Technical report, Institut national de la statistique et de la démographie (INSD). http://www.insd.bf/n/index.php/publications?id=151.

Kidane, Weldeghaber, Materne Maetz and Philippe Dardel (2006), 'Food security and agricultural development in sub-saharan africa', FAO, Subregional Office for Southern and East Africa, Rom 
Kruger, A, S Lemke, Mars Phometsi, H Van't Riet, AE Pienaar and G Kotze (2006), 'Poverty and household food security of black south african farm workers: the legacy of social inequalities', Public health nutrition 9(07), 830-836.

Melgar-Quinonez, Hugo R, Ana C Zubieta, Barbara MkNelly, Anastase Nteziyaremye, Maria Filipinas D Gerardo and Christopher Dunford (2006), 'Household food insecurity and food expenditure in bolivia, burkina faso, and the philippines', The Journal of nutrition 136(5), 1431S-1437S.

SESRTCIC (2007), Food security and poverty alleviation initiative in the oic member states of sub-saharan africa: A preamble to cassava integrated project, Report 35p, Statistical, Economic and Social Research and Training Center for Islamic Countries (SESRTCIC).

USAID (2014), Fapda country fact sheet on food and agriculture policy trends - burkina faso, Fact sheet No 13760 4p, Food and Agriculture Policy Decision Analysis (FAPDA) - FAO.

USAID (2015a), Burkina faso agriculture and food security, Fact sheet 1p, US Agency for International Development.

USAID (2015b), Sahel - food insecurity and complex emergency, Fact sheet 8p, US Agency for International Development.

Wojtys, Malgorzata, Giampiero Marra and Rosalba Radice (2016), 'Copula regression spline sample selection models: the r package semiparsamplesel', Journal of Statistical Software 71(6).

Zidouemba, Patrice and Françoise Gérard (2014), 'Poverty and food security in burkina faso: Analysis of dynamics at work and impacts of public investment in agriculture'. 